Int. J. Morphol.,

35(1):371-375, 2017

\title{
Semen Bovino Sexado Congelado-Descongelado en Producción de Embriones In vitro
}

\author{
In Vitro Embryo Production with Frozen-Thawed Bovine Semen Sexed
}

Larocca, C. ${ }^{1} \&$ Filipiak, . $^{1}$

LAROCCA, C. \& FILIPIAK, Y. Semen bovino sexado congelado-descongelado en producción de embriones in vitro. Int. J. Morphol., 35(1):368-370, 2017.

RESUMEN: El objetivo de este trabajo fue evaluar la fertilidad in vitro del semen bovino sexado (SX) vs. no sexado (NS) congelado-descongelado de dos toros Holstein, cada uno de la misma partida. Determinar el sexo de las crías significa un avance importante para la producción. El citómetro de flujo separa los espermatozoides X e Y por diferencia de ADN (4 \% mayor en X), con 90 $\%$ de efectividad. Los complejos ovocito-cúmulus (COC) se obtuvieron de folículos de 2 a 8 mm de ovarios de frigorífico, se cultivaron para maduración 22 h en TCM-199 + $5 \%$ de SFB + $10 \%$ licor folicular bovino (LFB), en gotas de $100 \mu l$, cubiertos con aceite mineral, en incubadora $\left(38,5^{\circ} \mathrm{C}, 5 \% \mathrm{CO}_{2}\right.$ y $95 \%$ de humedad). Posmaduración, se formaron al azar 4 grupos de COC los cuales fueron inseminados con NS y SX de los toros 1 y 2 . Los COC se incluyeron en gotas de $100 \mu$ l a razón de 10 COC por gota de semen capacitado a una concentración de $2 \times 10^{6}$ espermatozoides $/ \mathrm{ml}$ en todos los grupos, incubados durante $6 \mathrm{~h}$. Posteriormente se cultivaron en CR1aa $+5 \%$ $\mathrm{SFB}$, en incubadora. A las $48 \mathrm{~h}$ se evaluó el clivaje y al día 7 el desarrollo embrionario. Los resultados fueron analizados con el Test de $\chi^{2}$. Se encontró diferencias significativas en el toro 1 en el desarrollo embrionario a favor del NS (p<0,05). En el toro 2 no se encontró diferencias significativas en el clivaje ni en el desarrollo $(\mathrm{p}<0,05)$.

PALABRAS CLAVE: Semen sexado; Fertilización in vitro; Bovinos; Embriones.

\section{INTRODUCCIÓN}

Los avances tecnológicos han tenido una gran influencia en la evolución de la industria lechera. La criopreservación del semen junto a la inseminación artificial (IA), marcaron un hito desde la década de 1940. Otras tecnologías permiten hoy varias alternativas para incrementar la eficiencia reproductiva en rodeos lecheros. Una de las más recientes biotecnologías es el sexado de espermatozoides. La posibilidad de predecir el sexo especialmente en la producción lechera, representa un avance significativo. Se ha intentado por diversos métodos contar con la posibilidad de elegir el sexo de las crías. Esto se podría lograr sexando embriones bovinos por reacción en cadena de la polimerasa (PCR), método invasivo que requiere toma de biopsias de los embriones, reduce la tasa de gestación como consecuencia de las manipulaciones a las que son sometidos y es laborioso (Ferré \& Cattaneo, 2013). El sexado de semen resulta una alternativa válida.

El uso del citómetro de flujo que utiliza el ADN como marcador para la identificación de los espermatozoides por su cromosoma sexual, permite seleccionar el sexo de los mismos, lo cual es un aporte con un futuro trascendental en la ganadería bovina. Esta tecnología para predeterminar el sexo en animales domésticos fue usada satisfactoriamente en varias especies, según describen, Rath et al. (1999), Lindsey et al. (2001) y Evans et al. (2004).

El citómetro de flujo detecta la pequeña diferencia de ADN entre los cromosomas X e Y (aproximadamente $4 \%$ en bovinos) y los separa con precisiones de alrededor de un 90 \% (Xu et al., 2009). Los espermatozoides son sometidos a un colorante específico (bisbenzimidazol, Hoechst 33342) que se fija de manera selectiva al ADN (Schenk et al., 1999), que genera fluorescencia cuando es sometido a luz ultravioleta emitida por un láser de onda corta; la fluorescencia que emite el espermatozoide $\mathrm{X}$ es un $4 \%$ mayor comparado con la emitida por el espermatozoide Y (Seidel, 2007) y puede ser medida. El semen se somete a vibración a alta frecuencia causando la forma-

${ }^{1}$ Facultad de Veterinaria. Área Biotecnología de la Reproducción, Departamento de Reproducción Animal. Universidad de la República. Montevideo, Uruguay. 
ción de gotas individuales. Las gotas que se generan son cargadas positiva o negativamente, dependiendo del contenido de ADN detectado (Schenk et al.). Los espermatozoides muertos, los que tienen morfología anormal y aquellos en los que no se detecte su contenido de ADN con precisión, no se cargan y son eliminadas como desecho. Las gotas cargadas positivamente o negativamente son desviadas por una placa con la carga opuesta de manera que el esperma es dirigido a un vaso colector para cada una, de forma que los espermatozoides $\mathrm{X}$ van a un vaso colector y los espermatozoides $\mathrm{Y}$ a otro y el desecho a otro. Asimismo, la velocidad de clasificación de los espermatozoides se ha incrementado desde 350.000 espermatozoides por hora en la década de los 80 (Rath et al.), a 15-20 millones de espermatozoides/hora (Hamano et al., 2007). Actualmente, se pueden producir unas 6 a 8 dosis inseminantes por hora, con una eficacia promedio del $90 \%$ del sexo deseado (Ferré \& Cattaneo). Sin embargo, la velocidad de sexado sigue siendo un cuello de botella para su aplicación en inseminación artificial, debido a la baja concentración de espermatozoides en cada dosis de semen sexado (1,5-2 millones/pajuela de 0,25 $\mathrm{ml}$ ) lo cual puede ser un factor de la menor tasa de concepción con respecto al uso de semen no sexado (NS) (Xu et al., 2009). En todo el proceso se recupera solo del 10-15\% del semen que entra al citómetro de flujo, lo cual aumenta el costo.

En los países y/o centros de investigación que no pueden acceder por su costo al citómetro de flujo, la investigación para poder potenciar esta técnica está reducida a la posdescongelación.

La Fertilización in vitro (FIV) se ha usado en la industria ganadera hace ya algunas décadas, el primer ternero vivo, obtenido por FIV, nació en 1981 (Cran et al., 1993). Los primeros terneros nacidos por FIV con SX, nacieron en 1993 (Cran et al., 1993). Se han hecho desde entonces estudios en diferentes partes del mundo y en diferentes especies que han contribuido a la efectividad de la técnica (Zhang $e t$ al., 2003; Lu \& Seidel Jr., 2004; Xu et al., 2006; Trigal et al., 2012).

A pesar de estos y otros estudios que demuestran la posibilidad del uso de SX en FIV, para producir ganado del sexo deseado, desde el punto de vista productivo esta técnica está aún muy poco desarrollada. Por otro lado, la FIV también constituye un modelo experimental para estudiar la fertilidad del semen sexado comercial.

Por ser la FIV una alternativa para el uso del SX, sumada al auge de la aplicación de la técnica de aspiración folicular in vivo guiada por ultrasonografía (OPU), traería mayores beneficios ya que se obtienen más embriones a menor costo.
En producción de leche, el valor de las terneras es muy superior al de los terneros. Los productores de leche están interesados en predeterminar el sexo de sus productos de alta calidad genética, debido a la necesidad de incrementar el porcentaje de reemplazos y al mismo tiempo evitar los gastos de mantenimiento de los terneros, incrementando de esta forma la rentabilidad de sus establecimientos.

DeJarnette et al. (2008), reportan un $90 \%$ de hembras en 3.300 partos, usando SX en IA, comparado con un $48 \%$ de hembras con semen convencional en más de 11.000 partos. Xu et al. (2006) obtuvieron 96,5\% de hembras.

Considerando que la tasa de gestación para vaquillonas Holstein fuese de un promedio de $67 \%$, al utilizar semen sexado se reduciría en aproximadamente un 20 \% según reportan Xu et al. (2009).

Comparando los resultados en 100 vaquillonas inseminadas con NS y 100 vaquillonas con SX, teniendo en cuenta la relación macho/hembra 50/50 en los nacimientos, con el primero se obtendrían 33 hembras, mientras que utilizando el segundo con relación macho/ hembra 10/90, se obtendrían 42 hembras ( 9 terneras más).

El objetivo de esta investigación fue evaluar la fertilidad del semen bovino sexado Holstein congeladodescongelado, de 2 toros, mediante la producción por FIV de embriones desarrollados a estadíos transferibles.

\section{MATERIAL Y MÉTODO}

Los complejos cúmulo ovocito (COC), se obtuvieron de ovarios bovinos con menos de 5 horas de faenadas, provenientes de frigoríficos, transportados en solución salina isotónica a $37^{\circ} \mathrm{C}$. El contenido de los folículos de 2 a $8 \mathrm{~mm}$ de diámetro se aspiró mediante jeringa con aguja hipodérmica $18 \mathrm{G}$, utilizando medio buffer fosfato salino modificado (m-PBS), con $5 \%$ de SFB y antibióticos (Penicilina-Estreptomicina). Se utilizaron los COC, clase A (normas de la IETS).

Los COC se lavaron 3 veces en m-PBS en cajas de Petri de $35 \mathrm{~mm}$ de diámetro y se cultivaron para su maduración en TCM-199 + $5 \%$ de SFB + $10 \%$ de LFB, en gotas de $100 \mu \mathrm{l}$ en grupos de 20 ovocitos por gota, cubiertos con aceite mineral, en incubadora $\left(38,5{ }^{\circ} \mathrm{C}, 5\right.$ $\%$ de $\mathrm{CO}_{2}$ y $90-95 \%$ de humedad) por 22 horas. 
El LFB se obtuvo mediante aspiración de folículos de más de $15 \mathrm{~mm}$ de diámetro, se centrifugó 2 veces a $700 \mathrm{G}$, inactivándose a $56{ }^{\circ} \mathrm{C}$ durante 30 minutos.

Para la fecundación in vitro se formaron 4 grupos al azar con igual número de COC y se inseminaron según el grupo con NS del toro 1 (T1NS), SX del toro 1 (T1SX), NS del toro 2 (T2NS) y SX del toro 2 (T2SX), en las mismas condiciones, usando semen de la misma partida.

Las pajuelas de semen (NS, 0,5 ml y SX, 0,25 ml) fueron descongeladas 10 segundos a temperatura ambiente y 30 segundos a $35^{\circ} \mathrm{C}$ en baño María. La capacitación se realizó por centrifugación en medio $\mathrm{BO}$ de lavado de semen $(500 \mathrm{G})$, se aspiró el sobrenadante y el pellet que quedó en el fondo del tubo se diluyó con solución BO de dilución de semen a una concentración de $2 \times 10^{6}$ espermatozoides/ml (para todos los grupos). Se formaron gotas de $100 \mathrm{ml}$ con el semen en platina caliente $\left(35^{\circ} \mathrm{C}\right)$, se cubrieron con aceite mineral y se colocaron los ovocitos madurados, en una relación de 10 COC por gota.

El cocultivo se mantuvo por 6 horas en incubadora. Luego de la fecundación los ovocitos se denudaron mediante agitación en vortex en medio TCM-199 HEPES, con $5 \%$ de SFB y antibióticos por 5 minutos.

Los presuntos cigotos de los grupos se cultivaron para desarrollo en medio CR1aa $+5 \%$ de SFB, en incubadora.

Se estudió la tasa de división (clivaje) a las 48 horas en la cual se contabilizó la cantidad de ovocitos divididos con respecto a la cantidad de ovocitos sometidos a fertilización para cada toro con NS y SX. A los 7 días desde la fecundación se evaluó el desarrollo in vitro de los embriones a blastocistos.

Análisis estadístico: se utilizó el Test de $\chi^{2}$. Los análisis se realizaron con nivel de significación del $5 \%$.

Tabla I. Toro 1, SX y NS en la tasa de división y producción de embriones

\begin{tabular}{lcll}
\hline Grupo & Número total de ovocitos & Tasa de División & Desarrollo embrionario \\
\hline T1NS & 242 & $159(66 \%) \mathrm{a}$ & $122(50 \%) \mathrm{a}$ \\
T1SX & 290 & $213(73 \%) \mathrm{a}$ & $111(38 \%) \mathrm{b}$ \\
\hline
\end{tabular}

Distintos superíndices difieren significativamente $(\mathrm{p}<0,05)$.

Tabla II. Toro 2, SX y NS en la tasa de división y producción de embriones

\begin{tabular}{lcll}
\hline Grupo & Número total de ovocitos & Tasa de División & Desarrollo embrionario \\
\hline T2NS & 227 & $139(61 \%) \mathrm{a}$ & $117(51 \%) \mathrm{a}$ \\
T2SX & 273 & $182(67 \%) \mathrm{a}$ & $132(48 \%) \mathrm{a}$ \\
\hline
\end{tabular}

Distintos superíndices difieren significativamente $(\mathrm{p}<0,05)$.

\section{RESULTADOS Y DISCUSIÓN}

Los resultados de la FIV con SX y SN de los toros 1 y 2, se muestran en las Tablas I y II.

Se encontró diferencias significativas en el toro 1 en el desarrollo embrionario a favor del NS $(p<0,05)$. En el toro 2 no se encontró diferencias significativas en el clivaje ni en el desarrollo $(\mathrm{p}<0,05)$.

Los estudios de Xu et al. (2009), con SX en FIV obtuvieron un clivaje de $61,7 \pm 0 \%$ y un $20,2 \pm 2,5 \%$ de desarrollo agregando fructosa además de albúmina bovina (BSA) al medio de desarrollo, en esta investigación se obtuvieron resultados mayores tanto en clivaje como en desarrollo embrionario al utilizar semen sexado. Wilson et al. (2006), sostienen la necesidad de estudios que evalúen el comportamiento in vitro de SX y NS, congelado-descongelado del mismo toro y en lo posible del mismo eyaculado a la descongelación. Ellos al estudiar el SX y NS de diferentes toros en FIV no obtuvieron diferencias en la tasa de clivaje, sin embargo obtuvieron diferencias significativas en la producción de embriones a favor del NS. En el presente trabajo en el toro 1 se encontró diferencias significativas en el desarrollo para el SN, coincidiendo con Wilson et al., mientras que en el toro 2 no hubo diferencias significativas. Wheeler et al. (2006), en la tasa de clivaje para ambos sémenes no obtuvo diferencias significativas, pero sí obtuvo mayor desarrollo embrionario para el NS respecto al SX (30-40 \%, vs. 10-20\% respectivamente). 
Estudiando el semen de 5 toros en FIV, Trigal et al. obtuvieron mayor clivaje y mayor desarrollo de embriones (diferencias significativas), en el NS, respecto al SX. Coinciden los resultados en el desarrollo embrionario al utilizar el semen del toro 1 , en el toro 2 no hay diferencias ni en el clivaje, ni en el desarrollo embrionario.

Kastska-Ksiaz kiewicz et al. (2006), utilizando SX, semen sexado Y (SY) y NS (congelado-decongelado), reportan diferencias significativas en la tasa de clivaje del NS respecto al semen sexado (X e Y), sin embargo el desarrollo embrionario a blastocistos fue similar para el NS y el SX, lo cual coincide con el desarrollo embrionario en el toro 2.

Puglisi et al. (2006), estudiando el comportamiento en la FIV de SX y NS provenientes de diferentes toros, reportan una menor tasa de clivaje para el SX, no encontrando diferencias significativas en el desarrollo embrionario. En forma similar a los resultados de KastskaKsia $z$ kiewicz et al. y de Puglisi et al., en este experimento hubo diferencias significativas en el desarrollo de embriones provenientes del toro 1 a favor del NS, pero no del toro 2 .
Es posible que las diferencias significativas encontradas en el clivaje con SX en el toro 1, puedan deberse a un efecto individual lo cual para ser demostrado conllevaría un estudio de mayor número de toros.

De este estudio se desprende que la FIV puede ser una herramienta para producir embriones de sexo deseado en la producción bovina, aumentando los remplazos y disminuyendo el costo relativo del semen sexado al obtenerse mayor cantidad de embriones.

La aplicación del semen sexado-X (SX) en combinación con otras biotecnologías reproductivas podría implementarse potenciando los beneficios de ambas. Cuando se usa SX en IA, con cada pajuela que contiene 1,5$2 \times 10^{6}$ de espermatozoides, en el mejor de los casos se fertiliza un ovocito in vivo. En cambio, en Fertilización in vitro (FIV), tan poco como 1.000 espermatozoides pueden ser usados por ovocito a fertilizar (Yang et al., 1993).

\section{AGRADECIMIENTOS} Pechiar.

A Luis Rosés, Dra. Ana Aznares y Dra. Elizabeth
LAROCCA, C. \& FILIPIAK, Y. In vitro embryo production with frozen-thawed bovine semen sexed. Int. J. Morphol., 35(1):368-370, 2017.

SUMMARY: The objective of this study was to evaluate the in vitro fertility of sexed (SX) vs. non-sexed (NS), frozen-thawed bovine semen from two Holstein bull, from the same batch each one. Offspring sexing represents an important advance for livestock production. Flow cytometry separates X and Y spermatozoa by difference in DNA (4\% greater in X) with $90 \%$ effectiveness. Cumulus-oocytes complexes (COC) were obtained from follicles measuring between 2 and $8 \mathrm{~mm}$ collected from slaughterhouse ovaries; they were then cultured $22 \mathrm{~h}$ for maturation in TCM-199 + $5 \%$ BFS $+10 \%$ bovine follicular fluid (BFF) in $100 \mu 1$ drops with mineral oil, in incubator $\left(38.5^{\circ} \mathrm{C}, 5 \% \mathrm{CO}_{2}\right.$ and $95 \%$ humidity). Postmaturation, 4 groups were randomly formed and inseminated with NS and SX of the 1 and 2 bulls, including them in $100 \mu 1$ drops at 10 COC per drop of capacitated semen diluted to a concentration of $2 \times 10^{6}$ sperms $/ \mathrm{ml}$ in all groups, incubated during $6 \mathrm{~h}$. They were then cultured in CR1aa $+5 \% \mathrm{BFS}$ in an incubator. At $48 \mathrm{~h}$ cleavage and at day 7 embryonic development, were assessed. Results were analyzed with $\chi^{2}$ square Test. There were significant differences $(\mathrm{P}<0.05)$ in the embryonic development in bull 1, grater in NS. In bull 2 there were not significant differences in cleavage neither in embryo development.

KEY WORDS: Sex sorted sperm; In vitro fertilization; Bovine; Embryos.

\section{REFERENCIAS BIBLIOGRÁFICAS}

Cran, D. G.; Johnson, L. A.; Miller, N. G.; Cochrane, D. \& Polge, C. Production of bovine calves following separation of $\mathrm{X}$ - and $\mathrm{Y}$ chromosome bearing sperm and in vivo fertilisation. Vet. Rec., 132(2):40-1, 1993.

DeJarnette, J. M.; Nebel, R. L.; Marshall, C. E.; Moreno, J. F.; McCleary, C. R. \& Lenz, R. W. Effect of sex-sorted sperm dosage on conception rates in Holstein heifers and lactating cows. J. Dairy Sci., 91(5):1778$85,2008$.

Evans, G.; Hollinshead, F. K. \& Maxwell, W. M. Preservation and artificial insemination of sexed semen in sheep. Reprod. Fertil. Dev., 16(4):455-64, 2004.
Ferré, L. \& Cattaneo, L. Biotecnologías reproductivas: producción in vitro de embriones y semen sexado. (¿La pareja perfecta?). Rev. Med. Vet. (B. Aires), 94(2):28-36, 2013.

Hamano, K. Sex preselection in bovine by separation of X- and Ychromosome bearing spermatozoa. J. Reprod. Dev., 53(1):27-38, 2007.

Kastska-Ksiaz kiewicz, L.; Rynska, B.; Bochenek M.; Opiela J. \& Jurkiewicz, J. In vitro production of bovine embryos using flow-cytometrically sexed sperm. Arch. Tierz. Dummerstorf, 49(2):133-40, 2006.

Lindsey, A. C.; Bruemmer, J. E. \& Squires, E. L. Low dose insemination of mares using non-sorted and sex-sorted sperm. Anim. Reprod. Sci., 68(3-4):279-89, 2001. 
Lu, K. H. \& Seidel Jr., G. E. Effects of heparin and sperm concentration on cleavage and blastocyst development rates of bovine oocytes inseminated with flow cytometrically-sorted sperm. Theriogenology, 62(5):819-30, 2004.

Puglisi, R.; Vanni, R.; Galli, A.; Balduzzi, D.; Parati, K.; Bognioni, G.; Crotti, G.; Duchi, R.; Galli, C.; Lazzari, G. \& Aleandri, R. In vitro fertilisation with frozen-thawed bovine sperm sexed by flow cytometry and validated for accuracy by real-time PCR. Reproduction, 132(3):519-26, 2006

Rath, D.; Long, C. R.; Dobrinsky, J. R.; Welch, G. R.; Schreier, L. L. \& Johnson, L. A. In vitro production of sexed embryos for gender preselection: high-speed sorting of X-chromosome-bearing sperm to produce pigs after embryo transfer. J. Anim. Sci., 77(12):3346-52, 1999.

Schenk, J. L.; Suh, T. K.; Cran, D. G. \& Seidel, G. E. Jr. Cryopreservation of flow-sorted bovine spermatozoa. Theriogenology, 52(8):1375-91, 1999.

Seidel Jr., G. E. Economics of selecting for sex: the most important genetic trait. Theriogenology, 59(2):475-85, 2003.

Seidel, G. E. Jr. Overview of sexing sperm. Theriogenology, 68(3):4436, 2007.

Trigal, B.; Gómez, E.; Caamaño, J. N.; Muñoz, M.; Moreno, J.; Carrocera, S.; Martín, D. \& Diez, C. In vitro and in vivo quality of bovine embryos in vitro produced with sex-sorted sperm. Theriogenology, 78(7):146575, 2012.

Wheeler, M. B.; Rutledge, J. J.; Fischer-Brown, A.; VanEtten, T.; Malusky, S. \& Beebe, D. J. Application of sexed semen technology to in vitro embryo production in cattle. Theriogenology, 65(1):219-27, 2006.

Wilson, R. D.; Fricke, P. M.; Leibfried-Rutledge, M. L.; Rutledge, J. J.; Penfield, C. M. \& Weigel, K. A. In vitro production of bovine embryos using sex-sorted sperm. Theriogenology, 65(6):1007-15, 2006.

Xu, J.; Chaubal, S. A. \& Du, F. Optimizing IVF with sexed sperm in cattle. Theriogenology, 71(1):39-47, 2009.

Xu, J.; Guo, Z.; Su, L.; Nedambale, T. L.; Zhang, J.; Schenk, J.; Moreno, J. F.; Dinnyés, A.; Ji, W.; Tian, X. C.; Yang, X. \& Du, F. Developmental potential of vitrified holstein cattle embryos fertilized in vitro with sex-sorted sperm. J. Dairy Sci., 89(7):2510-8, 2006.

Yang, X.; Jiang, S. \& Foote, R. H. Bovine oocyte development following different oocyte maturation and sperm capacitation procedures. Mol. Reprod. Dev., 34(1):94-100, 1993.

Zhang, M.; Lu, K. H. \& Seidel Jr., G. E. Development of bovine embryos after in vitro fertilization of oocytes with flow cytometrically sorted, stained and unsorted sperm from different bulls. Theriogenology, 60(9):1657-63, 2003

\author{
Dirección para correspondencia \\ Dra. Clara Larocca \\ Área Biotecnología de la Reproducción \\ Facultad de Veterinaria \\ Universidad de la República \\ Montevideo \\ URUGUAY
}

E-mail: claralarocca@hotmail.com

Recibido : 09-08-2016

Aceptado: 25-11-2016 